\title{
An Investigation of Chinese Students Academic Performance, and Their Views on The Learning Experience, Associated with Flipped Team-Based Learning
}

\author{
Maryam Malekigorji, Dan Corbett, Lezley-Anne Hanna, Maurice Hall \\ Queen's University Belfast, Belfast, UK
}

\begin{abstract}
We report the implementation of team-based learning combined with flipped classroom (FTBL) learning as a major educational component of an undergraduate course within a UK joint college. The core components of FTBL were instituted in the course for non-native English-speaking students, who are studying in a satellite campus in China. Students' academic performance and course evaluation data gathered and compared with solely flipped classroom and traditional lecture-based courses. Students' perceptions of FTBL and traditional learning were investigated and compared through the use of a multi-dimensional and perceptual learning style preference questionnaire.

Students perceived that their experience of FTBL approach helped to develop useful knowledge and lifelong learning skills for their future academic life. Students' retention of knowledge within FTBL course (as judged by final examination scores) was significantly different from that resulting from the use of traditional teaching methodologies ( $t=12.2$, $p<.001)$. FTBL was observed to work exceptionally well in-classroom, increasing performance within classes $(p<.0005)$. Students provided more positive than negative comments and students' collaboration with one another was strongly associated with positive statements. Students provided more positive than negative comments and students' collaboration with one another was strongly associated with positive statements.
\end{abstract}

\section{Introduction}

During the past two decades, many UK universities have expanded their internationalisation activities in volume, scope, and complexity, introducing initiatives such as borderless higher education, study abroad programmes and student exchange programmes. These initiatives are being developed as a result of a number of factors, such as students' desire for life-long learning, the emergence of the 'knowledge economy,' and developments in the use of communication technologies, which can facilitate the delivery of such education [1].

Amongst different internationalisation strategies, International Branch Campuses (IBCs), which are physical manifestations of a home institution within another country, have become more commonplace
[2]. Currently universities are exporting education by recruiting international students to their home campuses [2]. Although these newly developed IBCs meet the general requirements of international higher education, and often assist their home institutions by providing international expertise and resources, they cause numerous administrative and educational challenges for both educators and students. It was proposed that IBCs should not provide an identical educational experience and they are required to localise the curriculum and pedagogy to adapt to the learning styles and context of the host University [1]. Therefore, a fundamental challenge for these institutions is to understand how much to localise their teaching activities to meet the needs of IBCs. Therefore, some appropriate educational strategies must be utilised to tackle IBC-related challenges such as technical English language proficiency and cultural differences in learning, as well as students' lack of familiarity with teaching approaches, assessment techniques, and educational ethos of institutions from other countries [1].

One area in which these IBCs are gaining attraction is within Asia. Considering the high ratio of Asian students across the UK Universities, different teaching strategies have previously been proposed to meet the needs of these learners studying in higher education [3]. It was proposed that Asian students consider listening comprehension and formal oral presentations the vital skills for academic achievements in graduate courses [1]. In 2016 Loucky and Ware introduced "Flipping Classes" (FP), which is a kind of student-cantered learning strategy, as an educational teaching method in order to increase Asian students' engagement [4].

While Asian students' academic success has been widely recognised, according to the literature, there are three main difficulties in learning for them who wish to obtain an English degree, namely: difference in learning style; cultural barriers; and language problems [1]. Interestingly, difficulties with academic content appeared to act as the major barrier to their academic performance rather than English language [5]. Asian students are reported to be passive recipients in education, described as being "spoon-fed" by educators. They seem to be more active in one-to one interactions with academics, as well as engaging in peer discussion outside the class [5]. In addition, anecdotal evidence gathered by the 
authors shows that Asian students are less likely to express their opinion, unless being asked, and also make use of repetitive strategies in learning. While Asian students are seen to change practices when integrated into the academic culture at a main campus [1], little is known about their behaviour at a remote/satellite campus. Moreover, reading, writing, listening and speaking as English language domains must be considered by the educators when creating or selecting teaching strategies and learning activities for a language-diverse classroom.

Learning in small groups has been used as a strategy within higher education since the 1970s [6], and often makes use of active teaching methods, such as group reading, writing, discussion, or problem solving, ultimately promoting analysis, synthesis, and evaluation of class content. However, despite the reported success of such approaches, many lecturers within higher healthcare education continue to dominate their instruction with traditional methods.

Active learning is an instructional method that requires students to actively engage in classroom activities and solve problems by themselves [6]. Classes applying active learning consist of many different techniques such as team-based learning (TBL), problem-based learning (PBL), and flipped classroom. PBL is usually applied in small group teaching and the tutor assigned problems to the students that are going to be discussed in the class to improve learning [7]. Flipped classroom is a learning approach that combines e-learning and face-to-face classroom activities. In this method classroom members preview lecture's material online and then they are actively engaged in different classroom tasks and workshops within a live lecture [1].

For classes with a large number of students, TBL seems to be a more special and in-depth approach as students can be organised into different teams to develop intra- and inter-group interactions more heavily than any other commonly applied teaching and learning strategies in higher education [8]. In a TBL course, students are normally assigned into permanent groups for the duration of the term, and the course content is organised into major units. Before any in-class content work, students are expected to preview assigned materials as each unit starts with the readiness assurance process (RAP) [8]. The RAP contains short questions on the learning outcomes that students preview individually and then students try to consensus on team answers. Students are given immediate feedback on the team tasks by the educators afterwards. Lecture section in RAP is normally very short and very focused which allows the educators to clarify any misperceptions and ambiguity that are detected during the team tasks. The pedagogic principles of TBL are based on four elements. Firstly, groups must be properly structured and managed. Secondly, students must be accountable for the quality of their individual preparations and group tasks. Thirdly, students should be provided frequent and timely feedback by the educators and finally, team tasks must promote both learning and team development [8].

There are many perceived advantages to using TBL. For example, TBL has been shown to contribute substantially to the enhancement of students' competitiveness and employability [8], and moreover, TBL has been shown to improve medical students' exam scores, when used in the place of small group lectures [9]. Courses taught with TBL typically involve multiple group assignments that are designed to improve learning and promote the development of self-managed learning teams [8]. It also contributes to research, allowing academic staff to engage in research-led teaching, bringing the latest business and scientific developments directly to the students. Furthermore, TBL approaches also encourage students to work independently and constructively at appropriate times, using academic staff as mentors and supervisors. Student-centred active learning strategies such as TBL also encourage students to pursue their own learning objectives and paths [9]. It has also been proposed that TBL courses produce statistically significant higher than average scores in end of term or national exams [10]. TBL approaches have the potential to encourage students to learn from their peers, make them more aware of the usefulness of collaboration, improve their ability to seek out information and allow them to perform better in their examinations [8].

In terms of English language practice, TBL has also been introduced into syllabi as a logical step in developing international learners' language skills, comprising of integration of language through communicative approaches, such as translation from mother tongue into English, reading, writing (notetaking), speaking (question answering and discussion) and listening to other class members [11].

The demand to increase enrolment within professional healthcare courses has increased in recent times. Healthcare education requires active participation of the learners and therefore educators have greatly focused to find techniques to increase students' performance leading to a growing interest in active learning strategies such as TBL. This is mainly due to the belief that active learning results in enhanced knowledge retention and skills application for healthcare professional students [12]. In 2012, a guideline for reporting TBL activities within Medical and Health Sciences Education literature was published [13]. In this guideline, seven core design elements were proposed that underlie the TBL method, and relate them to educational principles that enhance student engagement and learning within teams. Thompson et al. [14] examined factors 
influencing implementation of TBL within health science education, proposing that buy-in, expertise, resources, time, and course characteristics are the five main factors important to successful implementation of TBL. However, there is still a lack of adequate TBL implementation and evaluation in IBCs. Although many higher education classrooms are international in terms of the student body in onshore educational contexts, IBC students are normally studying their degree in an environment that English is not the first spoken language and there are cultural and learning strategies differences between the home campus and the host country. Therefore, IBCs might be expected to be different in learning and teaching implementations, such as TBL, or their educational consequences.

Pharmaceutical scientists and biotechnologists, as well as other medical-related professionals, are expected to become lifelong learners in order to deal with the dynamic challenges they face in relation to the fast pace of technological and scientific development. The application of TBL in this fashion within pharmacy and pharmaceutical education has increased in recent years, and many researchers have compared TBL with traditional lecture-based learning approaches in order to assess success.

As an example, Taglieri et al. [15] compared long-term knowledge retention in lecture-based versus flipped team-based learning course delivery, and whilst their result proposes that TBL can improve student engagement and mastery of material, knowledge retention in the long term was lower than lecture-based learning. However, around the same time, Remington et al. [16] analysed students' attitudes and perceptions regarding TBL and lectures in a pharmacotherapeutics course, finding that TBL enhanced their learning of course content, teamwork skills, and lifelong learning skills.

\section{Rationale and design of the study}

In 2014, Queen's University Belfast (QUB, Northern Ireland, UK) established a joint college with China medical University (CMU), located in Shenyang, People's Republic of China. During the first semester of the inaugural year of undergraduate teaching, a traditional teaching style was employed for students, all of whom were studying for bachelor's degrees in pharmaceutical sciences or Pharmaceutical biotechnology. Academic assessment at the end of this semester clearly indicated that the use of such an approach failed to bring about satisfactory student performance, which was reflected in module and teaching evaluation results as well as student's academic performance (i.e. over $60 \%$ failure rate in pharmaceutical and applied microbiology module). It was proposed that technical English language issues, cultural differences, students' lack of familiarity with UK university teaching approaches, their assessment techniques and educational ethos might have affected their satisfaction and academic performance. As a result, many different initiatives such as blended learning approaches, creation of technical dictionaries, weekly quiz, feedback sessions, and student peer mentoring schemes have been applied to tackle some of those mentioned educational issues.

This outcome led to the employment of a solely flipped classroom approach, which was found to bring about outcomes which were considerably more favourable and offer benefits in terms of both academic performance and student perceptions when compared to more traditional approaches [1]. The flipped classroom teaching approach employed here involved students watching short recorded lectures in preparation for in class activities, and the use of active and interactive learning approaches within the classroom. However, a number of educational issues such as student engagement, teamwork and collaborations were still apparent on completion of the transition to this educational approach. Considering that a growing body of literature conferring benefits of team-based active learning, it was decided that it may be beneficial to expose students to a novel (for the context) team-based learning strategy, called flipped TBL (FTBL), when TBL combined with flipped classroom, during their second year of undergraduate study. In this method, students are asked to watch the online lecture before each session and perform different class tasks as groups in an active learning style environment during each session.

In this study, FTBL approach was introduced to a cohort $(n=46)$ of entirely Chinese students within an industrial pharmaceutics module. Development of the design of the teaching methodology was initially considered via the collection of insight into how students felt about the effectiveness of different teaching modalities which had been previously utilised within the college.

In this study, students' perceptions of TBL and traditional learning were investigated and compared through the use of a multi-dimensional and perceptual learning style preference questionnaire. Feedback from teaching staff, coupled with the academic performance of students in previous semesters agrees with, and has further supports the suggestion that there are issues with traditional teaching strategies (i.e. the delivery of lectures, and the dissemination of large amounts of key knowledge during live taught sessions). Overall, active learning strategies, such as FTBL, may offer improvements in academic outcomes as previous research shows solely flipped classroom teaching style enhances students' collaboration, satisfaction and academic performance within courses at this College, but this can be further improved [1]. 


\section{Aims and objectives}

The aim of this study was to assess the differences in student perceptions, as well as classroom and academic performance, in relation to traditional lecture-based teaching versus flipped classroom and FTBL approaches. It was hypothesised that students would perform better in their examinations on materials covered by FTBL approach versus solely flipped classroom and traditional teaching styles. A variant of small group teaching, FTBL approach reported here emphasises student preparation out of class and application of knowledge in class. Students were organized strategically into diverse teams of 67 students, who worked together throughout the class. Before each unit or module of the course, students were directed to prepare by reading supplied and directed materials prior to class. This method then gave students the opportunity to make use of their new knowledge during class time. It is a learning philosophy according to which students must actively engage in finding problems, and the answers to these problems. Group work was central to exposing students to, and improving their ability to apply course content. With FTBL, the vast majority of class time was used for group work, rather than the traditional provision and retention of knowledge approach.

The objectives were to:

(i) Ascertain students' views on the different teaching styles

(ii) Measure classroom performance with regard to FTBL

(iii) Determine if academic performance differed for traditional teaching versus flipped classroom approach alone versus FTBL

\section{Methods}

The methodology and results are outlined under three separate sub-headings: 'Student perception', 'Student classroom performance' and 'Student academic performance'. Students' perception regarding different teaching modalities were analysed through the use of standard module evaluation questionnaire, and an in-depth understanding about student's perception regarding FTBL was achieved via the administration of an online research questionnaire. Student's classroom performance in FTBL course was also investigated and their final examination results in FTBL, solely flipped classroom and traditional lecture-based course were compared.

Before the introduction of FTBL, one session of training was provided to the students and the purpose of FTBL teaching approach was clearly explained and justified. This training also emphasised the value of team work and communication skills and commitment.

\subsection{Student perception}

In order to understand students' perception regarding different learning styles, standard module evaluation surveys from three modules delivered using either traditional methods, solely flipped classroom teaching, or a FTBL approach were gathered and analysed. Further, in order to understand and analyse students' perception in more depth towards FTBL, an online research questionnaire was designed. The standard module evaluation survey consisted of standard questions which make use of a 5-point Likert scale, with scores ranging from strongly disagree (1), to strongly agree (5). The research questionnaire was designed in a similar fashion and adapted from a previously employed questionnaire used to assess student perceptions relating to solely flipped classroom teaching [1] and is available on request from the corresponding author.

The 33-question survey included sections relating to students' demographics, and previous experience of being taught using FTBL, general questions about what students like or dislike regarding FTBL in general, attitudes towards teamwork, peer learning and collaborations in comparison with lecture-based learning styles, and other skills such as rapportbuilding skills, ability to influence others, timemanagement skills and problem solving. A further section listed items representing additional views on FTBL experiences such as sharing material, feedback by peers, random group member selection and group size. These questions were developed based on a combination of teacher reflection and discussion, and previous formal and informal students' feedback. Demographical information of participants, long answers and yes/no questions were not included in the statistical analysis.

The research questionnaire analysis produced four subscales and 18 items. Based on the nature of the questions and students' shared experiences, the four subscales were consequently named as (1) Positive Attitude Subscale (PAS), (2) FTBL versus Traditional Subscale (BTS), (3) Preference and Suggestion Subscale (PSS), and (4) Future Development Subscale (FDS). The PAS is comprised of three items regarding students' general positive attitudes about FTBL. These items enquired about the enhancement of classroom interactions, team working, learning from peers, and the usefulness of collaborations within the classes. The BTS contains eight items comparing FTBL and traditional teaching approaches in areas such as teamwork skills development, information seeking abilities, academic performance, retention of knowledge, outside the classroom collaboration, and increasing motivation 
and interests for higher engagements. The PSS has three items which describe students' attitudes towards sharing notes and materials between peers, group members' random selection and students' demand towards FTBL for their future academic learning. The last subscale, FDS, includes three items asking about the usefulness of FTBL in students' future career performance to become more effective team members, and their professional and academic development.

The research questionnaire was piloted by Chinese international students studying at QUB in the UK and the research protocol was subsequently approved by the QUB School of Pharmacy Research Ethics Board (School reference: 005PMY2017). Minor modifications to the research questionnaire were made based on feedback from piloting. The standard module evaluation survey did not require ethical approval as it fell under the definition of an audit (evaluation of a service being provided by the university) and is something that is routinely carried out at the end of each academic year. No identifiable information was gathered via the standard module evaluation survey and completion was entirely voluntary, with this being communicated clearly to the participants.

Students' response to standard module evaluation surveys and a further anonymous online questionnaire (operated by SurveyGizmo) was captured immediately after the module was completed (January 2017), to investigate students' conceptions of different instructional methods. Informed consent was electronically obtained at the initiation of the survey. Questionnaire design and phrasing was considered in order to maximise response rate, and made use of a question profile consisting of mainly closed questions. Further reminder emails were consistently used to try and maximise response rate.

\subsection{Students classroom performance}

Students were randomly (alphabetical allocations) organised into groups consisting of the same 6-7 members for the duration of the semester, and the course studied being organised into 15 major units. Before any in-class content work began, groups were required to study various lecture materials online, with each unit subsequently beginning with questions related to the content of these preparatory materials. This strategy not only indicates to the academic that the preparatory work has been completed, but also values all opinions.

Although these questions build on and formatively assess students' knowledge, FTBL strategy also intends to allow questions to generate group discussions and collaborations. Groups were then given seven questions in each session as a verbal exercise related to the unit subject, which was monitored by an academic staff via the assessment of groups' answers. Groups were given time (5 minutes) for each question to think and discuss about the possible answers. For each question, one group was selected randomly to answer the question in the class. All group members had to participate as questions could not be answered by the same group member in different sessions. In order to evaluate groups' classroom performance and academic improvement in due course, the group answer was marked by the academic staff delivered the course (with a total score of one hundred) via comparison with the model answer. All groups received feedback on the team test at the end of the semester, with an award being provided to the best performing group, as a further strategy to motivate students. Weekly averages of in-class performances were processed by using the mean of groups mark in each week, which were subsequently compared by use of an ANOVA.

\subsection{Students' academic performance}

Student's final examination results related to modules taught via different teaching strategies were gathered, which included final module marks, as well as students' scores in MCQ section and long answer questions within examinations and compared by the help of mean and standard deviation.

All data were consolidated into Microsoft Excel spreadsheets, analysed and processed by IBM SPSS 23.0. The statistical tools employed in this study were ANOVA and two-tailed Student t-test and $\mathrm{p}$ was set at $<0.05$ from the outset.

\section{Results}

\subsection{Students perception}

Response rate to the modulate evaluation survey and the research questionnaire were $88 \%$ and $100 \%$ respectively, and results only included those questionnaires, which were completed in their entirety (46 students (85\% female, 15\% male, aged 19-24)). Figure 1 shows that there were significant differences in perception on three out of eight learning factors between FTBL and the other two learning approaches.

The results of the paired t-test (Table 1) shows that students achieved significantly higher satisfaction rates when taught by FTBL, in comparison with solely flipped classroom and traditional teaching styles. Although only flipped classroom creates very active leaning environments for the students, students believe that they received higher support when flipped classroom is blended with TBL $(\mathrm{t}=2.03, \mathrm{p}<.05)$ (Table 1$)$. Students also perceived that time commitment to the course was more appropriate in FTBL, compared with flipped classroom $(t=2.22, p<.05)$. Statistical analysis of 
students' perception also showed that tutorials/ workshops were more beneficial in FTBL than flipped classroom teaching style $(\mathrm{t}=2.57, \mathrm{p}<.05)$ (Table 1).

The differences in students' perception between traditional teaching style and FTBL were significantly higher than the differences between solely flipped classroom and FTBL approaches (Table 1). In terms of FTBL approach, students perceived more opportunity to develop report writing skills $(\mathrm{t}=3.33, \mathrm{p}<.005)$ and believed that tutorials/workshops were more beneficial $(\mathrm{t}=2.73$, $\mathrm{p}$ $<$.005). There was also higher satisfaction in course time commitment $(\mathrm{t}=2.59, \mathrm{p}<.05)$ and staff support $(\mathrm{t}=2.34, \mathrm{p}<.05)$ in FTBL, in comparison with lecture-based teaching method (Table 1).

Regarding the online research questionnaire, 65\% of students reported that they had experience of being taught using a TBL approach during their previous studies. The reliability of the PAS (alphaPAS) and BTS (alphaBTS) subscales were 0.98 and 0.99, respectively. This value for PSS (alphaPSS) subscale was 0.83 and for FDS (alphaFDS) subscale was 0.99 , and the composite reliability of this 18-item instrument (alphacomposite) was 0.99 . These reliability values all reached satisfaction.

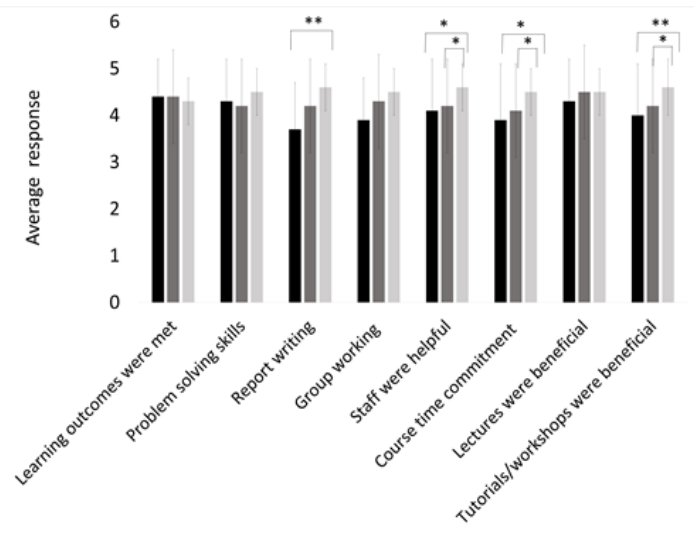

- Average response in a traditional teaching module $(n=46)$ - Average response in a flipped classroom module $(n=30)$ Average response in a FTBL module $(n=46)$

$* \mathrm{p}<.05$

$* * \mathrm{p}<.01$

Figure 1. Comparison of three modules evaluation survey with different teaching styles

In the PAS subscale, students agreed that FTBL made them aware of the usefulness of collaboration $(3.85 \pm 1.16)$ and learning from peers (Table 2). Students ranked FTBL in the BTS subscale as a superior method of learning in terms of developing team work skills (3.97 \pm 0.65$)$, information seeking ability (3.97 \pm 0.94$)$, data retention (3.85 \pm 1.16$)$, and academic performance within in- and outside classroom engagements, in comparison with lecturebased learning approaches.

Table 1. Results of matching paired-t test comparisons of all sub-scales between FTBL and solely flipped classroom styles and between FTBL and traditional teaching styles

\begin{tabular}{|c|c|c|c|c|c|}
\hline \multicolumn{6}{|c|}{ FTBL and solely flipped classr oom } \\
\hline Dimension/sub-scale & \multicolumn{2}{|l|}{$\begin{array}{l}\text { Learning } \\
\text { context }\end{array}$} & Mean & SD & $\mathrm{t}$ \\
\hline Learning outcomes & \multicolumn{2}{|c|}{$\begin{array}{l}\text { FTBL } \\
\text { Solely flipped } \\
\text { classroom }\end{array}$} & $\begin{array}{l}4.4 \\
4.4\end{array}$ & $\begin{array}{l}0.5 \\
0.5\end{array}$ & 0.39 \\
\hline $\begin{array}{l}\text { Problem solving } \\
\text { skills }\end{array}$ & \multicolumn{2}{|c|}{$\begin{array}{l}\text { FTBL } \\
\text { Solely flipped } \\
\text { classroom }\end{array}$} & $\begin{array}{l}4.6 \\
4.2\end{array}$ & $\begin{array}{l}0.5 \\
0.9\end{array}$ & 2.22 \\
\hline Report writing & \multicolumn{2}{|c|}{$\begin{array}{l}\text { FTBL } \\
\text { Solely flipped } \\
\text { classroom }\end{array}$} & $\begin{array}{l}4.5 \\
4.2\end{array}$ & $\begin{array}{l}0.5 \\
0.9\end{array}$ & 1.66 \\
\hline Group working & \multicolumn{2}{|c|}{$\begin{array}{l}\text { FTBL } \\
\text { Solely flipped } \\
\text { classroom }\end{array}$} & $\begin{array}{l}4.5 \\
4.3\end{array}$ & $\begin{array}{l}0.5 \\
0.9\end{array}$ & 1.11 \\
\hline Staff & \multicolumn{2}{|c|}{$\begin{array}{l}\text { FTBL } \\
\text { Solely flipped } \\
\text { classroom }\end{array}$} & $\begin{array}{l}4.6 \\
4.2\end{array}$ & $\begin{array}{c}0.5 \\
1\end{array}$ & $2.03 *$ \\
\hline $\begin{array}{l}\text { Course time } \\
\text { commitment }\end{array}$ & \multicolumn{2}{|c|}{$\begin{array}{l}\text { FTBL } \\
\text { Solely flipped } \\
\text { classroom }\end{array}$} & $\begin{array}{l}4.5 \\
4.1\end{array}$ & $\begin{array}{l}0.5 \\
0.9\end{array}$ & $2.22 *$ \\
\hline Lectures & \multicolumn{2}{|c|}{$\begin{array}{l}\text { FTBL } \\
\text { Solely flipped } \\
\text { classroom }\end{array}$} & $\begin{array}{l}4.5 \\
4.5\end{array}$ & $\begin{array}{l}0.5 \\
0.5\end{array}$ & 0.00 \\
\hline Tutorials/workshops & \multicolumn{2}{|c|}{$\begin{array}{l}\text { FTBL } \\
\text { Solely flipped } \\
\text { classroom }\end{array}$} & $\begin{array}{l}4.6 \\
4.2\end{array}$ & $\begin{array}{l}0.6 \\
0.7\end{array}$ & $2.57^{*}$ \\
\hline \multicolumn{6}{|c|}{ FT BL and traditional teaching } \\
\hline Dimension/sub-scale & $\begin{array}{l}\text { Learning } \\
\text { context }\end{array}$ & Mea & an $\mathrm{SI}$ & & $\mathrm{t}$ \\
\hline Learning outcomes & $\begin{array}{l}\text { FTBL } \\
\text { Traditional } \\
\text { teaching }\end{array}$ & $\begin{array}{l}4.4 \\
4.3\end{array}$ & $\begin{array}{l}0 . \\
0 .\end{array}$ & & 0.61 \\
\hline $\begin{array}{l}\text { Problem solving } \\
\text { skills }\end{array}$ & $\begin{array}{l}\text { FTBL } \\
\text { Traditional } \\
\text { teaching }\end{array}$ & $\begin{array}{l}4.6 \\
4.3\end{array}$ & $\begin{array}{l}0 . \\
0 .\end{array}$ & & 1.66 \\
\hline Report writing & $\begin{array}{l}\text { FTBL } \\
\text { Traditional } \\
\text { teaching }\end{array}$ & $\begin{array}{l}4.5 \\
3.9\end{array}$ & $\begin{array}{l}0 . \\
0 .\end{array}$ & & $3.33 * *$ \\
\hline Group working & $\begin{array}{l}\text { FTBL } \\
\text { Traditional } \\
\text { teaching }\end{array}$ & $\begin{array}{l}4.5 \\
4.3\end{array}$ & $\begin{array}{l}0 . \\
0 .\end{array}$ & & 1.11 \\
\hline Staff & $\begin{array}{l}\text { FTBL } \\
\text { Traditional } \\
\text { teaching }\end{array}$ & $\begin{array}{l}4.6 \\
4.1\end{array}$ & $\begin{array}{l}0 . \\
1 .\end{array}$ & & $2.34 *$ \\
\hline $\begin{array}{l}\text { Course time } \\
\text { commitment }\end{array}$ & $\begin{array}{l}\text { FTBL } \\
\text { Traditional } \\
\text { teaching }\end{array}$ & $\begin{array}{l}4.5 \\
3.9\end{array}$ & $\begin{array}{l}0 . \\
1 .\end{array}$ & & $2.59^{*}$ \\
\hline Lectures & $\begin{array}{l}\text { FTBL } \\
\text { Traditional } \\
\text { teaching }\end{array}$ & $\begin{array}{l}4.5 \\
4.3\end{array}$ & $\begin{array}{l}0 . \\
0 .\end{array}$ & & 1.11 \\
\hline Tutorials/workshops & $\begin{array}{l}\text { FTBL } \\
\text { Traditional } \\
\text { teaching }\end{array}$ & $\begin{array}{l}4.6 \\
4.0\end{array}$ & $\begin{array}{l}0 . \\
1 .\end{array}$ & & $2.73 * *$ \\
\hline
\end{tabular}

$* \mathrm{p}<.05$.

$* * \mathrm{p}<.01$ 
Within the PSS subscale, it was evident that students agreed to share their class notes, and appropriate study materials, with their peers during team-based exercises $(4.12 \pm 0.70)$ and would like to have more FTBL module within their degree course (3.52 \pm 0.57). However, results revealed that respondents would prefer to choose their teammates by themselves and not being chosen randomly (3.77 \pm 0.80) (see Table 2). Descriptive statistics of the subscale scores are also reflected in Table 3. In addition, students were asked to address if they were able to develop any additional skills not included in those four subscales mentioned above. Rapport building skills (58\%), problem solving skills (51\%) and self-study skills (47\%) were the most commonly cited skills stated by the students within this question (see Figure 2). Moreover, self-awareness skills (11\%), applying knowledge to practical situations (17\%) and innovative thinking skills (17\%) were the least cited skills.

Table 2. Subscales descriptions and descriptive statistics by item. The item number reflects the question number in the actual online questionnaire

\begin{tabular}{|lllll|}
\hline Subscale & Valid N & Mean & SD & t-value \\
\hline PAS & 120 & 3.88 & 0.55 & $4.60^{*}$ \\
\hline BTS & 315 & 3.88 & 0.27 & $5.08^{*}$ \\
\hline PPS & 120 & 3.81 & 0.61 & $5.06^{*}$ \\
\hline FDS & 154 & 3.86 & 0.66 & $5.48^{*}$ \\
\hline
\end{tabular}

Table 3. Descriptive statistics and one-sampled tvalues of 4 subscale scores

\begin{tabular}{|c|c|c|c|}
\hline Subscale & Item and description & Mean & SD \\
\hline \multirow[t]{3}{*}{1 (PAS) } & $\begin{array}{l}\text { 3. Team-based learning made me want to learn } \\
\text { from my peers. }\end{array}$ & 3.88 & 0.72 \\
\hline & $\begin{array}{l}\text { 4. Team-based learning allowed me to learn from } \\
\text { my peers. }\end{array}$ & 3.90 & 0.76 \\
\hline & $\begin{array}{l}\text { 6. Using team-based learning in class has made me } \\
\text { aware of the usefulness of collaboration. }\end{array}$ & 3.85 & 1.16 \\
\hline \multirow[t]{5}{*}{2 (BTS) } & $\begin{array}{l}\text { 5. Being taught in this way allowed me to develop } \\
\text { my team working skills more than traditional } \\
\text { teaching methods. }\end{array}$ & 3.97 & 0.65 \\
\hline & $\begin{array}{l}\text { 7. Team-based learning has improved my ability to } \\
\text { seek out information in comparison to traditional } \\
\text { teaching. }\end{array}$ & 3.97 & 0.74 \\
\hline & $\begin{array}{l}\text { 8. In comparison to traditional teaching methods, } \\
\text { team-based learning will allow me to perform } \\
\text { better in University. }\end{array}$ & 3.77 & 0.90 \\
\hline & $\begin{array}{l}\text { 9. I believe that team-based learning will help me } \\
\text { to remember what I have been taught more than } \\
\text { traditional teaching style. }\end{array}$ & 3.85 & 0.96 \\
\hline & $\begin{array}{l}\text { 21. Compared to the traditional teaching methods } \\
\text { that I have experienced, team-based exercises have }\end{array}$ & 3.85 & 1.35 \\
\hline
\end{tabular}

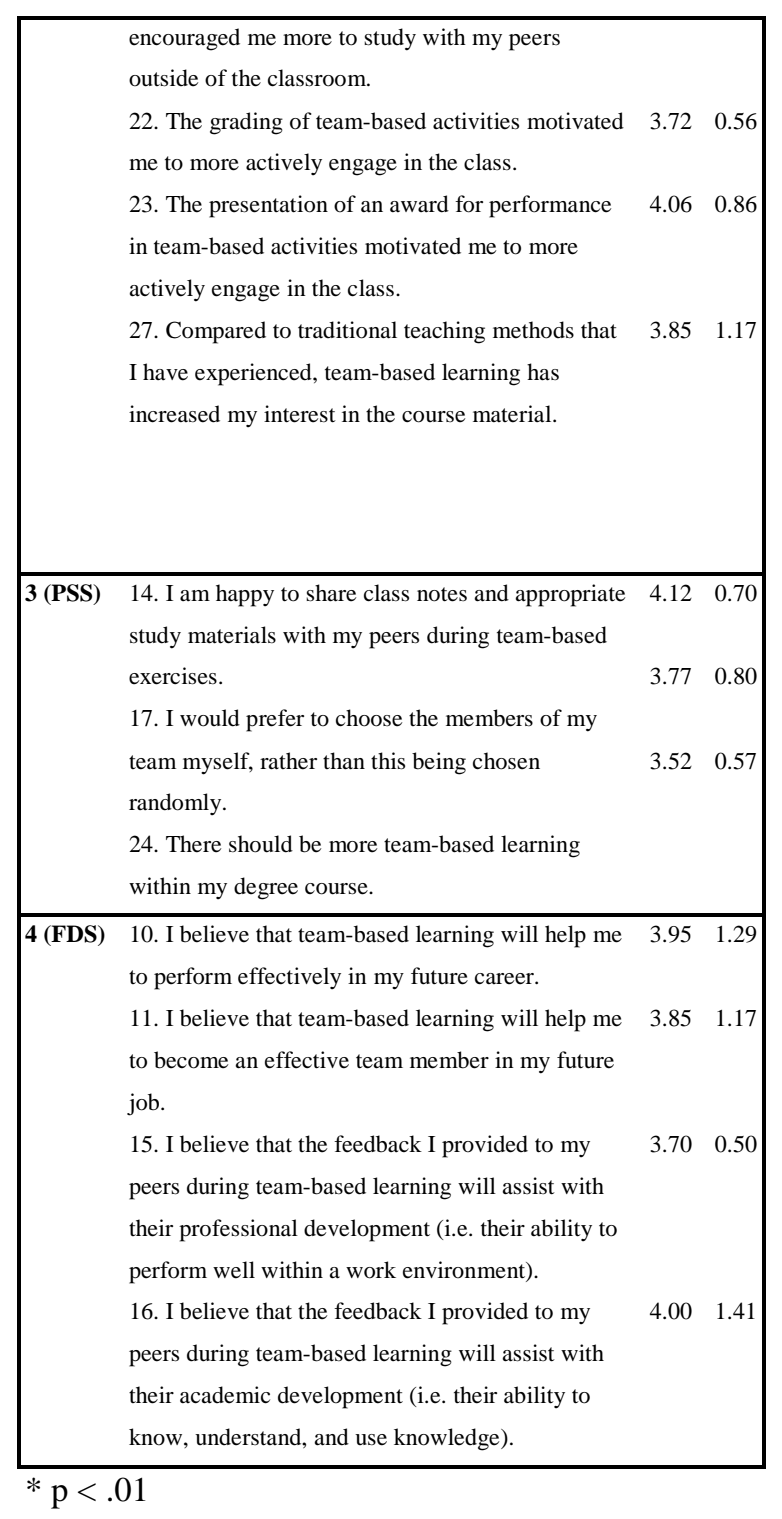

The respondents were provided with open ended questions which aimed to collect both positive and negative qualitative feedback regarding the FTBL approach. Students' attitudes, along with the frequency of comments, are extracted from the research survey and listed in Table 4.

The students' positive attitudes towards FTBL mainly referred to collaboration and teamwork, idea exchange, ability to concentrating and efficient learning of material. Comments also stated that students enjoyed this teaching style and that comprehension skills have been improved (Table 4).

Students' negative attitudes towards FTBL indicated that they would prefer to have chosen their own group partners, and that they believed FTBL to be time consuming. There were also comments addressing the imbalances relating to contribution from group members, the possibility of missing the key points of the class session, and feeling embarrassed by providing wrong answers during the class (Table 4). 
Students' class performance in 7 groups during the semester were monitored and their participations answering given questions were analysed (Figure 3). ANOVA analysis shows that class average performance increased significantly with time $(\mathrm{p}<$ .0005 ), from $4.74 \%$ in the first week to $61.79 \%$ in the last week of FTBL teaching, with the highest results being obtained during the last three weeks of the semester (see Table 5). The result suggests that groups were reluctant to participate in class activity on initiation of the strategy, but their engagement dramatically increased when the FTBL moved forward during the semester.

\subsection{Student's academic performance}

Statistical analysis of final examination results showed a significant difference $(\mathrm{t}=3.9, \mathrm{p}<.001)$ in performance within multiple choice questions (MCQs) sections, when examinations of material taught by FTBL and solely flipped classroom approaches were compared (Table 6). However, no considerable difference was detected between the mentioned teaching styles in long, essay-style questions within these examinations. The rate of failure (defined as an overall examination score of $<40 \%$ ) was seen to increase within the FTBL approach $(n=6)$, in comparison with solely flipped classroom style $(n=3)$. Moreover, the average of final module mark was slightly higher in FTBL but this difference was not significant $(\mathrm{t}=1.3, \mathrm{p}>.05)$ (see Table 6).

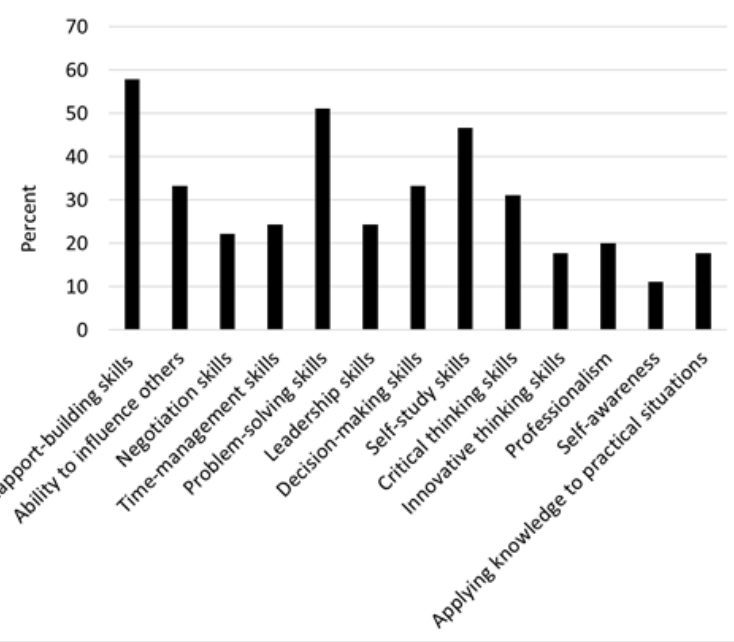

Figure 2. Students' perceptions regarding skills development by FTBL approach

Statistical analysis also indicates that students performed significantly better in the FTBL course in comparison to the traditionally-taught, lecture-based course, in regard to the MCQ section $(t=2.7, p<$
$.001)$, and long answer section $(\mathrm{t}=2.4, \mathrm{p}<.05)$ of the examination, in addition to the overall final examination and module final marks $(\mathrm{t}=12.2$, $\mathrm{p}<$ .001) (Table 6).

Table 4. Examples of students' positive and negative comments and frequency of each regarding FTBL approach

\begin{tabular}{|c|c|c|}
\hline \multicolumn{3}{|c|}{$\begin{array}{l}\text { Positive feedback } \\
\end{array}$} \\
\hline Key theme & Example verbatim quotation & $\begin{array}{l}\text { Frequency } \\
\text { (n) }\end{array}$ \\
\hline $\begin{array}{c}\text { Cooperation skills } \\
\text { development }\end{array}$ & $\begin{array}{l}\text { "I learnt how to cooperate with my } \\
\text { teammates during FTBL module." }\end{array}$ & 13 \\
\hline Facilitated sharing & $\begin{array}{l}\text { "Ilearnt how to share ideas, } \\
\text { experiences and knowledge with my } \\
\text { teammates during FTBL module." }\end{array}$ & 6 \\
\hline $\begin{array}{c}\text { Increased level of } \\
\text { interest }\end{array}$ & $\begin{array}{l}\text { "I enjoyed answering questions } \\
\text { during FTBL module." }\end{array}$ & 5 \\
\hline Academic progression & $\begin{array}{l}\text { "I progressed really well during } \\
\text { FTBL module." }\end{array}$ & 4 \\
\hline $\begin{array}{l}\text { Critical skills } \\
\text { development }\end{array}$ & $\begin{array}{l}\text { "FTBL approach improved my } \\
\text { critical thinking skill." }\end{array}$ & 4 \\
\hline Peer learning & $\begin{array}{l}\text { "My teammates can provide some } \\
\text { important points, which I may } \\
\text { ignore." }\end{array}$ & 4 \\
\hline Improved concentration & $\begin{array}{l}\text { "It helped me to concentrate more on } \\
\text { what the teacher said during the } \\
\text { dass." }\end{array}$ & 3 \\
\hline Mastery of the subject & $\begin{array}{l}\text { "It helped me to understand the } \\
\text { material very well." }\end{array}$ & 3 \\
\hline $\begin{array}{c}\text { Preparation skills } \\
\text { development }\end{array}$ & $\begin{array}{l}\text { "It promoted subjects preview } \\
\text { preparation skills." }\end{array}$ & 2 \\
\hline Increased engagement & $\begin{array}{l}\text { "Blend TBL approach increased } \\
\text { classroom engagement." }\end{array}$ & 2 \\
\hline TBL application & $\begin{array}{l}\text { "FTBL is really suitable active } \\
\text { learning style for chemistry and/or } \\
\text { biology subjects." }\end{array}$ & 1 \\
\hline $\begin{array}{c}\text { Presentation skills } \\
\text { development }\end{array}$ & $\begin{array}{l}\text { "FTBL approach improved my } \\
\text { presentation skills." }\end{array}$ & 1 \\
\hline Life skills development & $\begin{array}{l}\text { "TBL experience is useful in my day } \\
\text { to day life." }\end{array}$ & 1 \\
\hline Facilitated sharing & $\begin{array}{l}\text { "During the TBL module I had more } \\
\text { opportunity to share the material." }\end{array}$ & 1 \\
\hline \multirow[t]{2}{*}{ TBL suggestion } & $\begin{array}{l}\text { "I would like to have more } \\
\text { competitive tasks during FTBL } \\
\text { classes." }\end{array}$ & 1 \\
\hline & Negative feedback & \\
\hline Key theme & Example verbatim quotation & $\begin{array}{l}\text { Frequency } \\
\text { (n) }\end{array}$ \\
\hline Equal contribution & $\begin{array}{l}\text { "I was not satisfied with my teammates" } \\
\text { contributions during FTBL module." }\end{array}$ & 7 \\
\hline \multicolumn{2}{|c|}{ TBL timing "TBL is really time-consuming." } & 5 \\
\hline Group rigidity & $\begin{array}{l}\text { "I had to work with the same teammates } \\
\text { in the whole semester." }\end{array}$ & 3 \\
\hline \multicolumn{2}{|c|}{$\begin{array}{ll}\text { Task distribution } & \begin{array}{l}\text { "Some group members had more chance } \\
\text { to talk than others." }\end{array} \\
\end{array}$} & 3 \\
\hline Discussion time & $\begin{array}{l}\text { "The discussion time was not enough } \\
\text { during the dass." }\end{array}$ & 2 \\
\hline \multirow{2}{*}{$\begin{array}{c}\text { Feeling } \\
\text { embarrassed } \\
\text { Solidfocus on } \\
\text { TBL tasks }\end{array}$} & $\begin{array}{l}\text { "I felt awkward when I answered the } \\
\text { questions wrong." }\end{array}$ & 2 \\
\hline & $\begin{array}{l}\text { "Sometimes we only focused on the } \\
\text { material we might be questioned and may } \\
\text { ignore the rest of the material." }\end{array}$ & 2 \\
\hline Preview problems & $\begin{array}{l}\text { "It was hard to preview the module } \\
\text { material before each session." }\end{array}$ & 1 \\
\hline Decision making & $\begin{array}{l}\text { "It was hard sometimes to decide which } \\
\text { idea is correct within the group." }\end{array}$ & 1 \\
\hline Feeling annoyed & $\begin{array}{l}\text { "Students with less confidence, or } \\
\text { knowledge, etc... feel annoyed by } \\
\text { working in a small group." }\end{array}$ & 1 \\
\hline $\begin{array}{c}\text { Feeling } \\
\text { uncomfortable }\end{array}$ & $\begin{array}{l}\text { "I dd not fed comfortable to work with a } \\
\text { group member, who I did not know well } \\
\text { before." }\end{array}$ & 1 \\
\hline
\end{tabular}

Notably, the number of failures arising within examinations from the lecture-based module was very high within MCQ sections $(n=49)$, long answer section $(n=30)$ and the final mark $(n=33)$, whereas no failure was obtained in MCQ or long answer 
Table 5. Weekly class average performance in a FTBL classroom.

\begin{tabular}{|c|cc|}
\hline $\begin{array}{c}\text { Week } \\
\text { number }\end{array}$ & $\begin{array}{c}\text { Class average } \\
\text { performance (\%) }\end{array}$ & SD \\
\hline $\mathbf{1}$ & 4.74 & 8.10 \\
\hline $\mathbf{2}$ & 9.50 & 13.09 \\
\hline $\mathbf{3}$ & 14.24 & 11.48 \\
\hline $\mathbf{4}$ & 18.99 & 6.31 \\
\hline $\mathbf{5}$ & 18.99 & 6.31 \\
\hline $\mathbf{6}$ & 18.99 & 6.31 \\
\hline $\mathbf{7}$ & 16.61 & 9.61 \\
\hline $\mathbf{8}$ & 26.13 & 13.11 \\
\hline $\mathbf{9}$ & 30.89 & 20.22 \\
\hline $\mathbf{1 0}$ & 30.89 & 14.98 \\
\hline $\mathbf{1 1}$ & 28.53 & 15.83 \\
\hline $\mathbf{1 2}$ & 40.39 & 18.86 \\
\hline $\mathbf{1 3}$ & 68.91 & 26.22 \\
\hline $\mathbf{1 4}$ & 59.39 & 16.21 \\
\hline $\mathbf{1 5}$ & 61.79 & 26.72 \\
\hline
\end{tabular}

examination components within examinations related to the module taught via FTBL. Additionally, only three overall module fails were reported when this learning approach was employed (see Table 6).

Table 6. Results of matching paired-t test comparisons of FTBL and solely flipped classroom and between FTBL and traditional teaching regarding final examination and module final mark $(n=46)$

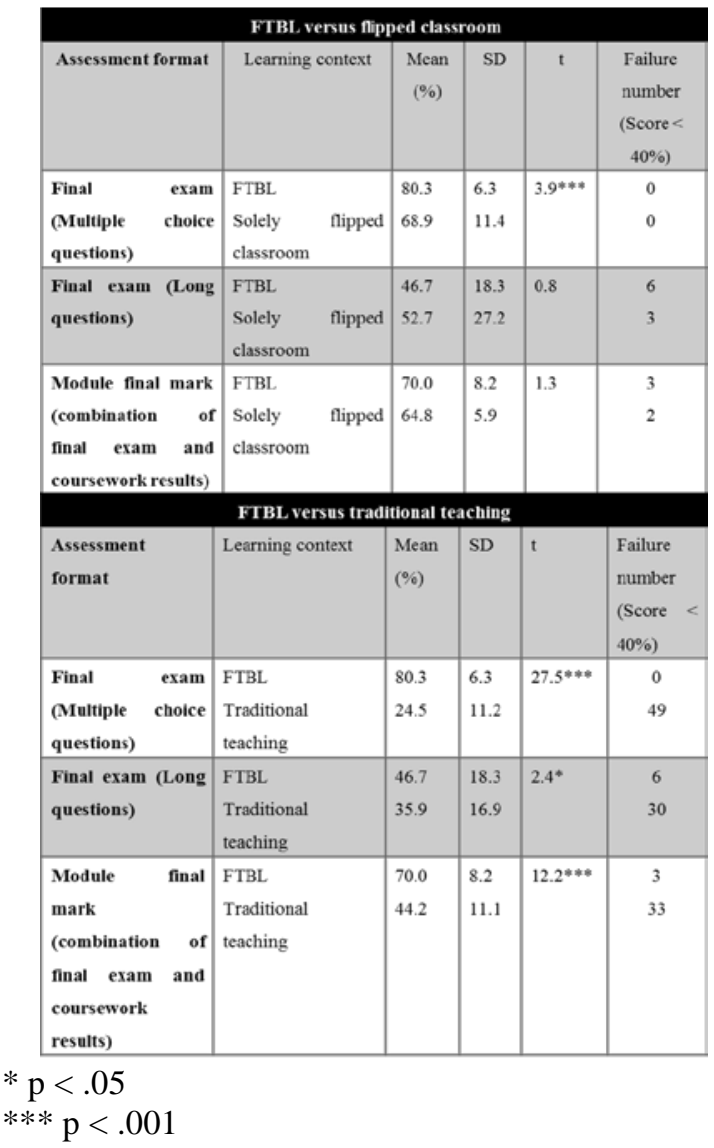

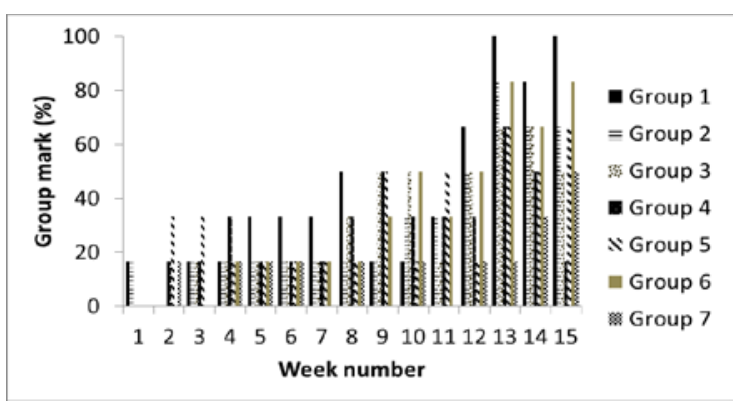

Figure 3. Students’ group performance in each week

\section{Discussion}

This work presents qualitative and quantitative evidence of the applicability and effectiveness of a flipped team-based learning approach within health science courses. This further supports the adaptability and versatility of FTBL strategy as an instructional strategy in our curriculum, a fact that has been established in other health professional courses [8], [10], [13], [14].

The use of FTBL as an active learning approach was selected due to its identified potential for the development of requisite skills for careers within the pharmaceutical sector, whilst also preparing students to handle routine questions in their future careers.

Course evaluation analysis between FTBL and sole flipped classroom teaching showed a slight increase in students' self-reported abilities to develop problem solving, report writing and group working skills within the FTBL course.

Improvements were also significant in terms of staff helpfulness, course time commitment and tutorials/workshops. This may be due to the higher level of student's motivation, engagement and collaboration within FTBL activities in comparison to traditional classroom activities such as tutorials and workshops. Course evaluation comparisons of FTBL and traditional lectures revealed higher student satisfaction with FTBL in all subscales, including report writing, staff helpfulness, course time commitment and tutorials/workshops, which is in line with other similar studies [9], [10], [16].

Research questionnaire analysis of students' rankings of FTBL methods with respect to intended instructional outcomes revealed significant improvement. Interestingly, $65.9 \%$ of the respondents would prefer to choose their teammates themselves, rather than being chosen randomly. Students' reluctance for being randomly selected might be due to the possible free-riding of group members, risk of grade inflation and difficult group dynamics. However, $75.9 \%$ of the students believed that everyone within their group was assigned an appropriate role within each activity. The negative feedback to the above question regarding assigned 
role might to be due to the teammates' absenteeism and unwillingness of members to take part in classroom activities, as both attendance, and participation were not compulsory.

$84.1 \%$ of the students stated the size of the group (6-7 members) was appropriate; $9.1 \%$ and 6.8\% reported the group size was too big and too small, respectively. Group size has considerable effect on, group performance effectiveness, resources usage, coordination and group management processes, and thus is an important consideration in the design of a group-based teaching methodology, such as the one detailed here. Although publications often do not distinguish clearly between dyads (two members), small groups (three to six members) and large groups (seven or more), evidence indicates that group size is associated with different interaction patterns or learning benefits, particularly if equal contribution or sharing resources are required [17]. Fuchs and colleagues [17] carried out a comparison study on dyadic and four-member groups and proposed that four-member group arrangements caused more cognitive conflict (negotiation and disagreement) in comparison with dyads, which seemed to be more suitable for average and high-achieving students. A non-significant trend was detected, which suited for dyads with regards to equal participation, particularly with low-achieving students. This research also claims that group size influences interaction equality and contribution to a shared resource.

$60 \%$ of the students within this study believed that there should be more FTBL within their degree course (15\% strongly agree and $45 \%$ agree), further reinforcing the perceived preference of the students for this approach. FTBL application within degrees operated at the IBC detailed here could be extended in a number of ways, including the use of forum discussions, group research projects and presentations/discussions. Research, presentation, revision and practical classes were the aspects of students' degree course that they believed are suitable to be taught using FTBL. However, some respondents stated that FTBL should not be applied to introduce new information and better to be used to recap the information. This kind of attitude might be due to challenges students face while previewing materials such as time management and selflearning, which at the end would be beneficial and makes them independent learners.

Comments were also indicated that FTBL is a useful technique which aids understanding of complex knowledge, but it is not an appropriate approach for subjects which merely need to be memorised, nor for fundamental subjects introduced in the first year of an undergraduate degree. However, the authors would challenge this idea as FTBL has been introduced as an effective active learning strategy to enhance knowledge retention, and has significantly improved the course performance, even in relation to fundamental subjects [10].

There were reluctances in relation to student participation at the beginning of the course; where low group engagement and score $(<30 \%$ class average performance) was obtained by week 8 . This may be due to the local and academic cultures students operate in within China, involving mostly teacher-centred primary and secondary education which students have experienced up to this point of their academic careers. While learning and teaching innovations have been applied around the world, to date, there is only limited number of examples of their use in mainland China, where lecture and case studies are still the predominant training programmes [18]. Teaching in higher education in China usually involves professors delivering theories, or respected practitioners reflecting practical guidelines for action based on their experience [18]. However, China with Confucian heritage culture (CHC), has been proven to share characteristics of a collectivist society, where cooperation of CHC's learners/ workers is strongly supported [19]. In this sense, TBL is not foreign to Chinses learners and might actually be framed as a familiar technique. By using dialectic FTBL that focuses on knowledge transformation, the authors hope to improve long-term knowledge retention, in-class engagement and student satisfaction. However, there are some limitations to the work mentioned such as self-reported data obtained from the questionnaire and short-term study involving a small part of the overall degree course. The authors tried to minimise those issues by the use of mixed methods approach (triangulation from different sources such as a research questionnaire, module evaluation survey and examination grades, which adds credibility to the findings).

The FTBL format allows for many different types of interactions, and one could further augment and improve the course in a number of ways, not least by the addition of various novel educational technology aspects, such as the use of student response systems, which may assist with individual engagement and development of growing confidence to answer questions.

Grading the FTBL sessions, as carried out within the approach here, has been found to increase the importance and value that students attach to these sessions that aligns with other TBL research available in the literature [20].

\section{Conclusion}

Making progress in IBCs requires an understanding of culture, learning and teaching experiences and adaptability of Western higher education in remote campuses. IBCs should flex their traditional teaching and learning styles over the creation and preservation of knowledge-even if 
their role as distributors of knowledge is subject to change, where critical learners themselves directly experience creating knowledge.

This work details a novel (for the context) flipped team-based learning approach, whereby class time was mainly spent carrying out various active learning activities, including those where students worked with each other to solve problems, answer group questions, watch short demonstrations and listen to and discuss key concepts. Students taught with FTBL achieved learning outcomes that were superior to classes taught using flipped classroom approaches exclusively, as well as those taught using traditional methods.

The transformative use of the blended classroom may be magnified by creating designed interaction treatments such as FTBL or group assignments that purposefully draw students into collaborative conditions, and have an encouraging effect on students' engagement with higher learning outcomes.

Our findings support our proposal that the FTBL improves student's satisfaction and academic performance in BSc pharmaceutical sciences and pharmaceutical biotechnology courses in China. For the purposes of this study, we recognised that Chinese students may require participation in active learning practices more than the UK students, due to the previous passive learning experiences. Further work will apply FTBL strategy more significantly within components relating to students' coursework such as practical sessions, where students' interaction and communication are crucial techniques related to satisfactory performance.

\section{References}

[1] D. Corbett, L. Hanna, M. Hall, D. Rooney, and M. Malekigorji, "Use of a "flipped classroom approach" to improve the learning experience and academic performance of pharmaceutical sciences students where English is not their first language", Higher Education Academy STEM conference, Manchester, United Kingdom, 2017.

[2] P.G. Altbach, and J. Knight, "The internationalization of higher education: motivations and realities”, J Stud Int, 2007, 11(3-4), 290-305.

[3] L.F. Zhang, and D. Watkins, D, "Cognitive development and student approaches to learning: An investigation of Perry's theory with Chinese and U.S”, Higher Education, 2001, 41 (3), 239-261.

[4] J.P. Loucky, and J.L. Ware, "Flipped Instruction Methods and Digital Technologies in the Language Learning Classroom”, IGI Global, Education, 2016.

[5] B. Lee, S.P. Farruggia, and G.T.L. Brown. “Academic difficulties encountered by East Asian international university students in New Zealand”, Higher Education, Research \& Development, 2013, 32 (6).
[6] R.M. Gillies, and A.F. Ashman, “An Historical Overview of the Use of Groups to Promote Socialization and Learning. Co-Operative Learning: The Social and Intellectual Outcomes of Learning in Groups, Routledge, 2003, 1-18.

[7] Y. Matsuka, R. Nakajima, H. Miki, et al, "A problembased learning tutorial for dental students regarding elderly residents in a nursing home in Japan” J Dent Educ, 2012, 76:1580-8.

[8] L. K. Michaelsen, and M. Sweet, "The essential elements of team-based learning”, Special Issue: TeamBased Learning: Small Group Learning's Next Big Step, 2008 116, 1-99.

[9] P.A, Thomas, and C. W. Bowen, “A controlled trial of team-based learning in an ambulatory medicine clerkship for medical students”, Teach Learn Med, 2011, 23 (1), 316.

[10] N.S. Vasan, D.O. DeFouw, and S. Compton, “Teambased learning in anatomy: An efficient, effective, and economical strategy”, Anat Sci, 2011, 4, 333-339.

[11] G. Kavaliauskiene, "Research into the Integration of Content-Based Instruction into the ESP Classroom", Journal of Language and Learning, 2004, 2 (1), ISSN 1740 $-4983$.

[12] L. Forsetlund, A. Bjørndal, A. Rashidian, et al, "Continuing education meetings and workshops: effects on professional practice and health care outcomes”. Cochrane Database Syst Rev, 2009.

[13] P. Haidet, R. E. Levine, D.X. Parmelee, S. Crow, et al, "Perspective: Guidelines for Reporting Team-Based Learning Activities in the Medical and Health Sciences, Education Literature”, Acad Med, 2012, 87, 3.

[14] B.M. Thompson, V.F. Schneider, P. Haidet, et al, "Factors Influencing Implementation of Team-Based Learning in Health Sciences Education", Academic Medicine, 2007, 82, 10.

[15] C. Taglieria, D. Schneeb, L. D., Camielc, et al, "Comparison of long-term knowledge retention in lecturebased versus flipped team-based learning course delivery", Currents in Pharmacy Teaching and Learning, 2017, 9, 391-397.

[16] T. L. Remington, B. E. Bleske, T. Bartholomew, et al, "Qualitative Analysis of Student Perceptions Comparing Team-based Learning and Traditional Lecture in a Pharmacotherapeutics Course". American Journal of Pharmaceutical Education, 2017, 81 (3), 55.

[17] L. S. Fuchs, D. Fuchs, S. Kazdan, K. Karns, et al, "Effects of workgroup structure and size on student productivity during collaborative work on complex tasks", Elementary School Journal, 2000, 100, 183-212.

[18] H. Q. Chu, and X. C. Cravens, "Principal Professional Development in China: Challenges, Opportunities, and Strategies”, Peabody Journal of Education, 2012, 87 (2): 178-199. 
[19] N, Phuong-Mai, C. Terlouw, and A. Pilot. "Cooperative learning vs Confucian heritage culture's collectivism: confrontation to reveal some cultural conflicts and mismatch”, Asia Europe, 2005, Journal, 3(3), 403-419.

[20] L.B. Krause, "The cognitive profile model of learning styles” J. Coll. Sci, 1998, Teaching, 28, 57-61. 